\title{
A Comparative Study on the Herd Behavior of Chinese Equity and Partial Equity Hybrid Funds -Empirical Analysis Based on Market Fluctuations
}

\author{
Jingyu Liu ${ }^{1}, \&$ Mingyang Liu $^{2}$ \\ ${ }^{1}$ International Business School, Jinan University, Zhuhai, China \\ ${ }^{2}$ Business School, Central South University, Changsha, China \\ Correspondence: Mingyang Liu, Business School, Central South University, Changsha, Hunan Province, No 932, \\ Lushan South Road, China.
}

Received: September 14, 2020

Accepted: October 13, 2020

Available online: October 22, 2020

doi:10.11114/aef.v7i6.5012

URL: https://doi.org/10.11114/aef.v7i6.5012

\begin{abstract}
This paper uses the LSV model and the VOL volatility index, as well as the quarterly position data of equity funds and partial equity hybrid funds from the first quarter of 2007 to the fourth quarter of 2019 to conduct an empirical study on the herd behavior of both kinds of funds. Then establish a connection with the volatility of the Shanghai Stock Exchange over the same period. The results show that the overall trend of herd behavior between equity funds and partial equity hybrid funds is almost completely opposite. Equity funds have a stronger herd behavior in buying, while partial equity hybrid funds have a stronger herd behavior in selling. Meanwhile, when the volatility of the Shanghai Composite Index increased significantly, the herd behavior in selling both increased.
\end{abstract}

Keywords: equity funds, partial equity hybrid funds, herd behavior, market volatility

\section{Introduction}

China's fund industry has developed rapidly since its inception in the 1990s. With the promulgation of relevant policies, such as the "Securities Investment Basic Law", the diversification and standardization of the fund market has been ensured, injecting vitality into the Chinese economy. In September 2001, Hua'an Fund Management Company established China's first open-end securities investment fund, Hua'an Innovation, which marked the development of China's fund industry has entered a new stage. Since then, the scale of open-end funds in China has expanded rapidly, showing an extraordinary development. Looking at the global fund industry, open-end funds have undoubtedly become the mainstream products of securities investment funds by virtue of their more market-oriented operating mechanisms and institutional arrangements. The research objects of this paper are two open-end funds which mainly invest in stocks, equity fund and partial equity hybrid fund. The equity fund was required that more than $80 \%$ of its fund assets must be invested in stocks by the "Administrative Measures for the Operation of Publicly Offered Securities Investment Funds" issued by the China Securities Regulatory Commission in 2014, while the partial equity hybrid fund's investment in stocks is generally $50 \%-70 \%$. In the first quarter of 2020 , the share of the market value of the stock market held by public funds in the market value of the Chinese stock market has further increased, and hit the highest level in the past five years. As of March 31, the market value of Chinese stocks held by public funds was 2.54 trillion CNY, accounting for $5.57 \%$ of the market value in circulation. Among them, the scale of partial equity hybrid funds is 1,037.794 billion, with a number of 3,076; the size of ordinary equity funds is 30.04 billion with a number of 449 . The two together accounted for $78.89 \%$ of all public fund holdings.

Herd behavior in the financial market is a special kind of irrational behavior. It refers to investors whose behavior is influenced by other investors under the circumstances of uncertain information environment to imitate the decisions of others, or they rely too much on public opinion and ignore their own information's value. Many studies have shown that the herd behavior of the Chinese securities market is obvious. Due to incomplete market information and imperfect regulatory systems, investors tend to choose the same investment strategy. Most fund holders in China favor short-term investment concepts, and fund companies are forced to abandon their original strategies to a certain extent and follow mainstream strategies. Meanwhile, the lack of a short-selling mechanism in the securities market makes the operating 
space of fund companies limited, so they choose the same investment strategy, which intensifies the 'herd behavior'. It is worth noting that although individual investors have always been the main investors of securities investment funds in the traditional sense, more and more institutional investors have poured into the market, and the investment behavior of institutional investors may become reference standards of the individuals, promoting the occurrence of herd behavior in market decision-making process. This paper focuses on the differences in herd behavior of all equity funds and partial share hybrid funds in the market, and the influence of their herd behavior on market volatility.

\section{Literature Review}

The herd behavior of the fund has been a hot topic in academic circles for a long time. With the development of domestic and foreign funds and the gradual improvement of the system, many experts and scholars are committed to exploring the herd behavior of different types of funds in various regions, grasping the trends of institutional investors and individual investors in the market, in order to form a fund market with effective information disclosure. Scholars mainly conduct empirical research from three aspects: the causes of herd behavior, the performance of herd behavior and its consequences. The mainstream theories are divided into information flow-based herd behavior proposed by Banerjee (Abhijit V. Banerjee, 1992), the reputation-based herd behavior proposed by Stein and Stein (David S. Scharfstein \& Jeremy C. Stein, 1990) and the reward-based herd behavior proposed by Maug and Naik (Ernst Maug \& Narayan Naik, 2011).

There are two main methods for empirical testing of herd behavior: one is the stock trading volume measurement method represented by the LSV model and the PCM model, and the second is the transaction price dispersion measurement represented by the CSSD model and the CSAD model. Josef and Robert W. (Lakonishok Josef \& Vishny Robert W., 1992) first proposed the LSV model in 1992 to study the herd behavior of institutional investors, and found that American fund managers did not show significant herd behavior. However, because the LSV model has the disadvantage of not being able to distinguish between "herd behavior" and "pseudo-herd behavior" formed by the collective response of investors to disclosed information, many scholars have improved it or selected other models for joint research. Deng and Qiao (Xin Deng \& Zheng Qiao, 2018) used the LSV model improved by Wermers (Russ Wermers, 1999) found that herd behavior will reduce the quality of company information disclosure, and it is correlated with the stock price plummet.

Meanwhile, Guney and Komba (Yilmaz Guney \& Gabriel Komba, 2016) conducted research on 8 emerging markets in Africa and found that the herd behavior in emerging markets is significantly severer than that in mature markets in Europe and America. Koch (Andrew Koch, 2016) conducted an empirical study on American mutual funds based on the perspective of informed trading, and found that the "leader" of the fund is more likely to obtain valuable information in advance to guide the rest of the fund. Brown and Wermers (Nerissa C. Brown \& Russ Wermers, 2014) found that the opinions of analysts can also significantly trigger the follow-up effect of fund managers. At the same time, Philippa et al. (Nikolaos Philippas, Fotini Economou \& Alexandros Kostakis, 2013) found that the large fluctuations in the stock market did not promote the herd behavior of the market in response to the investment behavior of U.S. equity and real estate investment trusts. This is opposite to the conclusion discovered by Bekiros et al. (Stelios Bekirows, Mouna Jlassi, Brian Lucey \& gazi Uddin, 2017), since they find that there is a significant positive correlation between volatility and the herd behavior, which reflects that the performance of herd behavior is not necessarily the same in different markets and different periods, and also reflects the importance of our need to follow up market research for a long time.

After a large number of scholars' research, the current measurement methods for herd behavior are relatively mature, but there is considerable controversy over the connection between fund herd behavior and market fluctuations, and there is a lack of comparison between the characteristics of herd behavior of different kinds of funds. There is also a lack of discussion on the causes of herd behavior, thus it is difficult to provide policy recommendations to the regulatory agencies. Based on the current research gaps, this paper proposes a comparative study of the herd behavior of equity and partial equity hybrid funds, then establish a connection with stock market volatility.

\section{Model Selection and Data Processing}

\subsection{Model Selection}

At present, there are a large number of methods to measure the degree of herd behavior. The traditional methods include the LSV model to measure the investor's trading direction, the CSSD model and the CSAD model to measure the dispersion of trading prices. As the most classic model for measuring herd behavior, the LSV model has the disadvantage of not being able to distinguish between the pseudo-herd behavior based on the same public information and the source of the herd behavior, but it can measure the impact of different funds from the direction of fund trading. The transactional convergence of the same stock is very suitable for measuring the overall level of herd behavior in the market. After the development of Wermers (Russ Wermers, 1999), the shortcomings of the LSV model's inability to identify the source of the herd behavior were well resolved, and the reliability of the LSV model was greatly improved. 
Based on the above advantages, considering that the research problem of this paper is the difference in the overall herd behavior of all equity funds and partial equity hybrid funds in the market, and the influence of herd behavior on market volatility, we have selected Wermers (Russ Wermers, 1999) The extended LSV model is tested empirically.

The LSV model can study the cross-sectional trading data of specific stocks and measure the convergence of traders' trading directions. For the same specific stock, based on the assumption of independent decision-making by each investor, if the number of funds adopting a buying strategy is significantly lower or higher than its average level, it indicates that there is obvious herd behavior. Define $H M_{i, t}$ as the herd behavior index of fund buying and selling $i$ stock in $t$ period, which is:

$$
H M_{i, t}=\left|P_{i, t}-P_{t}\right|-A F_{i, t}
$$

Among them, $P_{i, t}$ is the proportion of funds that have net purchases of $i$ stocks in period $t$ to all funds, namely:

$$
P_{i, t}=\frac{B_{i, t}}{N_{i, t}}
$$

Among them:

$$
N_{i, t}=B_{i, t}+S_{i, t}
$$

Among them, $B_{i, t}$ is the number of funds that bought $i$ stocks during the period $t$, and $S_{i, t}$ is the number of funds that sold $i$ stocks during the t period. And $P_{t}$ is the expected value of $P_{i, t}$, which represents the average value of the proportion of funds that bought stock $i$ during the period $t$, expressed by the formula:

$$
E\left(P_{i, t}\right)=\frac{\sum_{i=1}^{n} B_{i, t}}{\sum_{i=1}^{n} B_{i, t}+\sum_{i=1}^{n} S_{i, t}}
$$

$A F_{i, t}$ is an adjustment factor, which represents the expected value of $\left|P_{i, t}-P_{t}\right|$ on the premise that there is no herd behavior, the formula is:

$$
A F_{i, t}=E\left(\left|P_{i, t}-P_{t}\right|\right)
$$

Assuming that there is no herd behavior in the market, that is, all fund buying and selling decisions are independent, then $B_{i, t}$ should obey the binomial distribution with parameters $\left(N_{i, t}, P_{t}\right)$, so at this time $A F_{i, t}$ should be:

$$
A F_{i, t}=\sum_{k=0}^{N_{i, t}}\left|\frac{k}{N_{i, t}}-P_{t}\right| C_{N_{i, t}}^{k} P_{t}^{k}\left(1-P_{t}\right)^{N_{i, t}-k}
$$

Under the condition of a large sample $\left(N_{i, t}>100\right)$, the normal distribution can be used to approximate $B_{i, t}$. After approximation, the expression of $A F_{i, t}$ is:

$$
A F_{i, t}=\frac{\sqrt{P_{i, t}\left(1-P_{i, t}\right)}}{\sqrt{N_{i, t}}} \sqrt{\frac{2}{\pi}}
$$

The LSV model has a flaw in that it cannot distinguish whether the herd behavior of the fund comes from buying behavior or selling. Therefore, this paper further uses the buying herd behavior index BHM and the selling herd behavior index SHM proposed by Wermers (Russ Wermers, 1999) to measure two different herd behaviors. The formula is:

$$
B H M_{i, t}=H M_{i, t} \mid P_{i, t}>P_{t}
$$




$$
S H M_{i, t}=H M_{i, t} \mid P_{i, t}<P_{t}
$$

$B H M_{i, t}$ refers to the value of $H M_{i, t}$ when the proportion of funds that bought stock $i$ during $t$ period is greater than the average purchase ratio of all stocks during $i$ period, and $S H M_{i, t}$ is just the opposite, which refers to the value of $H M_{i, t}$ when the proportion of funds that bought stock $i$ during $t$ is less than the average purchase proportion of all stocks during $t$. Moreover, this paper introduces the volatility $V O L_{t}$ indicator to measure the overall volatility of the Chinese stock market as an auxiliary analysis. The formula is:

$$
V O L_{t}=\sqrt{\frac{\sum_{j=1}^{n}\left(r_{j}-r_{t}\right)^{2}}{n-1}}
$$

Among them, $r_{j}$ is the daily return rate of the Shanghai Composite Index on trading day $j$, and $r_{t}$ represents the average daily return rate of the Shanghai Composite Index during $t$.

\subsection{Data Processing}

Chinese equity funds and partial equity hybrid funds disclose the position details of the top ten largest stock positions every quarter. If a stock does not appear in two adjacent quarterly statements, it is impossible to measure the changes in its holdings. It is because that the reason why a stock fell out of the top ten largest positions of the fund can be the reduction of holdings, or it either can be the decline in stock prices. Therefore, the smaller the data interval is, the lower probability of drastic changes in positions has, and then more accurate the analysis results are. Moreover, China started the share-trading reform in September 2005 and was basically completed by the end of 2006, laying the institutional framework for a fully circulating stock market and laying the foundation for the development of institutional investors, especially securities investment funds. Therefore, this paper selects the top ten stock positions in the quarterly reports of equity funds and partial equity hybrid funds from the first quarter of 2007 to the fourth quarter of 2019 as the research objects.

In addition, since it is difficult for individual stocks with too few trading funds to measure herd behavior through the LSV model, this paper chooses to exclude funds with less than 3 stocks holding. This paper also excludes all index funds, because such funds passively follow the index rather than subjective transactions, and do not meet the definition of herd behavior.

For the measurement of stock market volatility, this paper uses the opening price minus closing price of all trading days from the first trading day of 2007 to the last trading day of the Shanghai Stock Exchange as the daily yield data to calculate the volatility index. $V O L_{t}$, the following is the empirical test result of this paper.

\section{Empirical test results and analysis}

Table 1. Index table of herd behavior of equity funds and partial equity hybrid funds

\begin{tabular}{|c|c|c|c|c|c|c|}
\hline Fund Category & \multicolumn{3}{|c|}{ Equity fund } & \multicolumn{3}{|c|}{ Partial equity hybrid fund } \\
\hline Herd behavior index & $\overline{H M}$ & $\overline{B H M}$ & $\overline{S H M}$ & $\overline{H M}$ & $\overline{B H M}$ & $\overline{S H M}$ \\
\hline 2007 & $0.0447^{* * *}$ & $0.0620^{* *}$ & $0.0307^{*}$ & 0.00303 & -0.0113 & $0.0178^{*}$ \\
\hline 2008 & $0.0609^{* * *}$ & $0.0502^{* *}$ & $0.0723^{* * *}$ & 0.0111 & $0.0152^{*}$ & 0.00665 \\
\hline 2009 & 0.0196 & 0.0144 & 0.0248 & 0.00766 & $0.0154^{* *}$ & -0.000108 \\
\hline 2010 & $0.0449^{* * *}$ & $0.0574^{* *}$ & 0.0335 & $0.0313^{* * *}$ & 0.00991 & $0.0546^{* * *}$ \\
\hline 2011 & $0.0286^{* *}$ & $0.0253^{*}$ & 0.0320 & $0.0301^{* * *}$ & -0.00333 & $0.0691^{* * *}$ \\
\hline 2012 & $0.0324^{* *}$ & $0.0436^{* *}$ & 0.0213 & $0.0204^{* *}$ & $0.0384^{* * *}$ & 0.00348 \\
\hline 2013 & $0.0293^{* *}$ & 0.0241 & $0.0348^{*}$ & $0.0383^{* * *}$ & $0.0375^{* * *}$ & $0.0391^{* * *}$ \\
\hline 2014 & 0.0221 & $0.071^{* * *}$ & -0.0113 & $0.0424^{* * *}$ & $0.0393^{* * *}$ & $0.0454^{* * *}$ \\
\hline 2015 & 0.0136 & $0.0242^{* *}$ & 0.00341 & $0.0505^{* * *}$ & $0.0648^{* * *}$ & $0.0369^{* * *}$ \\
\hline 2016 & $0.0160^{* * *}$ & -0.00689 & $0.0419^{* * *}$ & $0.0614^{* * *}$ & $0.0383^{* * *}$ & $0.0875^{* * *}$ \\
\hline 2017 & $0.0338^{* * *}$ & $0.0164^{* *}$ & $0.0531^{* * *}$ & $0.0175^{*}$ & $0.0231^{* *}$ & 0.0115 \\
\hline 2018 & $0.0465^{* * *}$ & $0.0387^{* * *}$ & $0.0544^{* * *}$ & -0.0183 & $0.0324^{* * *}$ & $-0.0696^{* * *}$ \\
\hline 2019 & $0.0580^{* * *}$ & $0.0604^{* * *}$ & $0.0557^{* * *}$ & $-0.0495^{* * *}$ & -0.00817 & $-0.0911^{* * *}$ \\
\hline
\end{tabular}

Note: $* * *$ means that the $\mathrm{z}$-test result is significantly not 0 at the $1 \%$ significance level, $* *$ means that the $\mathrm{z}$-test result is significantly not 0 at the $5 \%$ significance level, and * means that the z-test result is at $10 \%$ Significance is not 0 at the significance level, and no superscript means that the z-test result is not significant at the $10 \%$ significance level. 
Table 2. Volatility index VOL table of Shanghai Composite Index

\begin{tabular}{|c|c|c|c|c|}
\hline VOL & First quarter & Second quarter & Third quarter & Fourth quarter \\
\hline 2007 & 0.024918 & 0.022790 & 0.017886 & 0.017696 \\
\hline 2008 & 0.024542 & 0.027182 & 0.023381 & 0.027747 \\
\hline 2009 & 0.019506 & 0.013698 & 0.021192 & 0.014969 \\
\hline 2010 & 0.011426 & 0.016131 & 0.011444 & 0.014620 \\
\hline 2011 & 0.011070 & 0.009562 & 0.011059 & 0.011877 \\
\hline 2012 & 0.012703 & 0.008790 & 0.009434 & 0.010123 \\
\hline 2013 & 0.011242 & 0.011901 & 0.010388 & 0.009290 \\
\hline 2014 & 0.009243 & 0.007376 & 0.007261 & 0.014460 \\
\hline 2015 & 0.014376 & 0.024037 & 0.028012 & 0.015181 \\
\hline 2016 & 0.024079 & 0.010754 & 0.007189 & 0.006296 \\
\hline 2017 & 0.004923 & 0.005404 & 0.004891 & 0.005748 \\
\hline 2018 & 0.008231 & 0.009047 & 0.011515 & 0.012973 \\
\hline 2019 & 0.011739 & 0.011505 & 0.007226 & 0.006290 \\
\hline
\end{tabular}

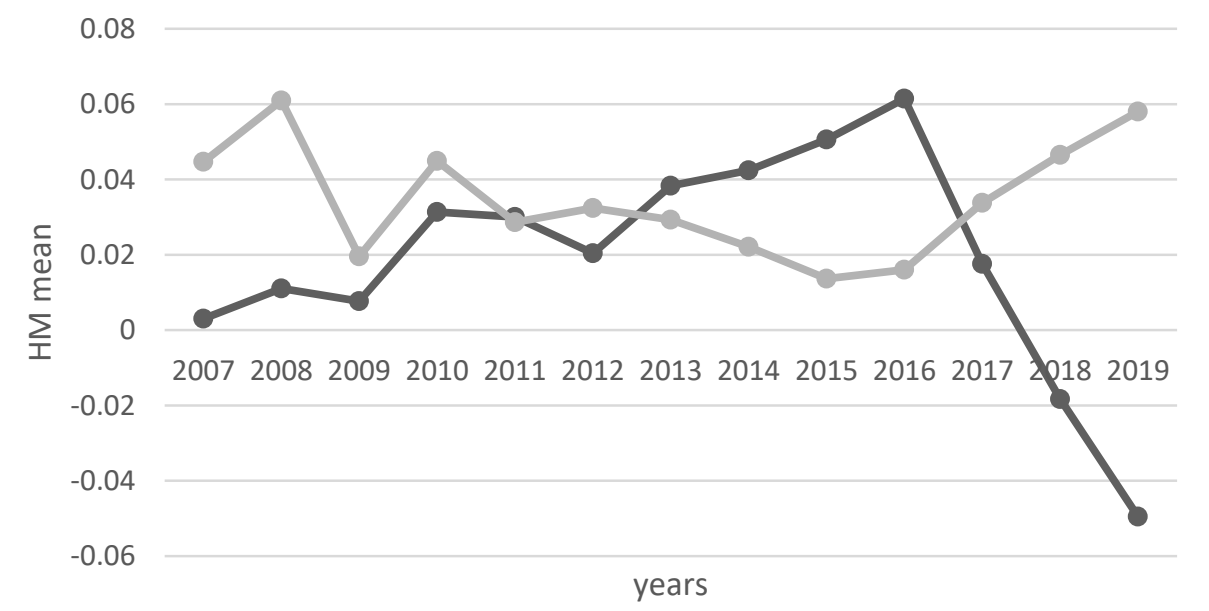

$\mathrm{HM}$ mean of partial equity hybrid funds $\longrightarrow \mathrm{HM}$ mean of equity funds

Figure 1. HM Mean of Partial equity Hybrid Funds and Equity Funds

Judging from figure 1, the herd behavior of equity funds and partial equity hybrid funds has shown two almost completely opposite trends, and the year 2016 has become a turning point for the two trends. Before 2016, the herd behavior of equity funds showed a fluctuating downward trend, while the herd behavior of partial equity hybrid funds showed a fluctuating upward trend. After 2016, the two trends were completely reversed. The herd behavior of equity funds began to rise rapidly, while the herd behavior of partial equity hybrid funds fell precipitously. For this phenomenon, there are two major reasons:

Firstly, there were two consecutive stock market crashes in 2015 and 2016, which had a huge impact on both market confidence and the investment decisions of fund managers. After two crashes, fund managers had to re-examine their investment ideas. It was after the stock market crash that Chinese stock market began to show very strong sector characteristics. In 2017, the blue-chip stocks in the Chinese stock market ushered in a full-blown explosion, the overall preference of the market has changed to blue chip stocks with stable operating conditions and strong profitability. In 2019, the market trend changed again, the market preference shifted to technology stocks, and the concentration of fund investment styles was still very high.

Secondly, in August 2015, the China Securities Regulatory Commission increased the minimum position limit for equity funds from $60 \%$ to $80 \%$ for reasons such as controlling market downside risks. During the transition period before the new position regulations came into effect, 371 equity funds from 67 fund companies were transformed into partial equity hybrid funds, accounting for $68.3 \%$ of the total equity funds that year. The increase in the minimum position limit has further reduced the trading freedom of equity funds, making fund managers more cautious in their investment methods, and more inclined to follow suit strategies that seem to be less risky in a short period of time. But this behavior will actually further increase the hidden risk of the stock. 


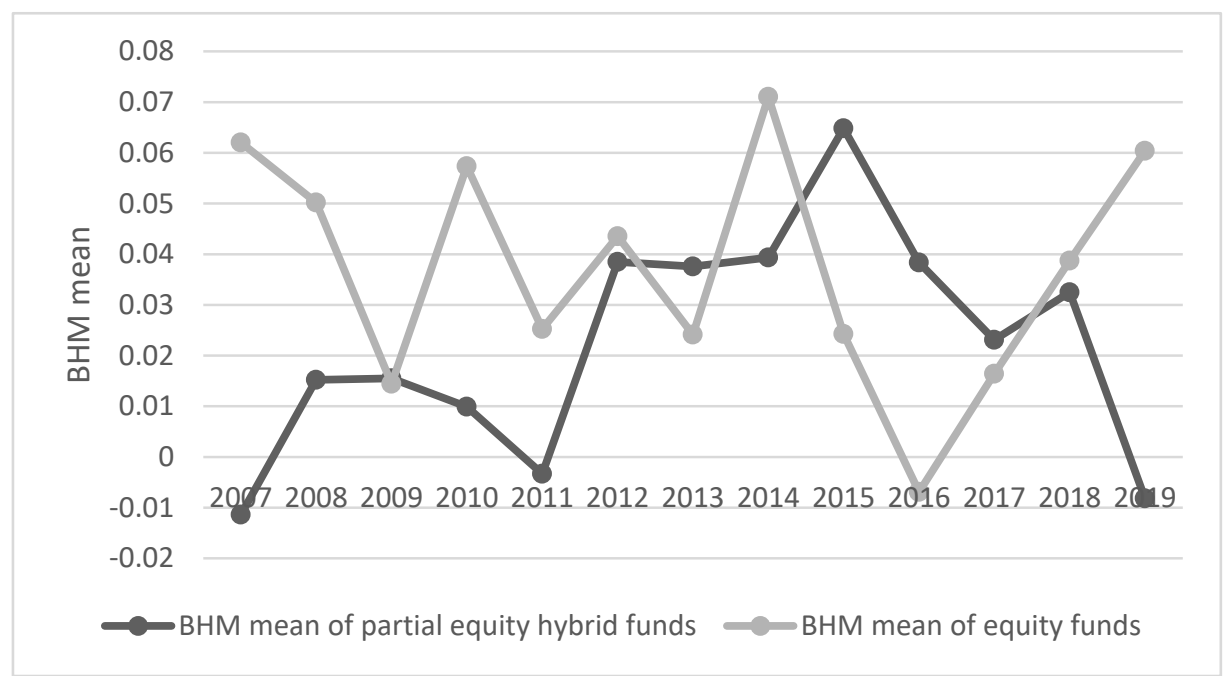

Figure 2. BHM Mean of Partial equity Hybrid Funds and Equity Funds

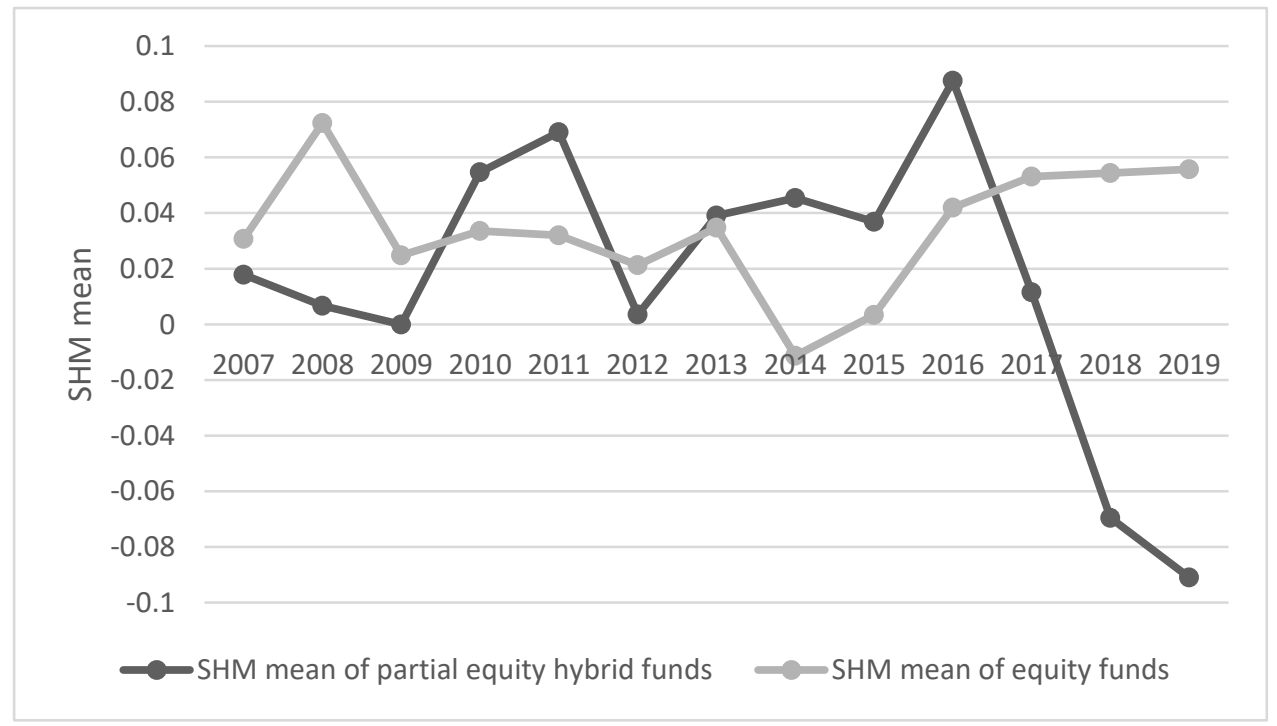

Figure 3. SHM Mean of Partial equity Hybrid Funds and Equity Funds

Figure 2 and Figure 3 show that the BHM index of equity funds was higher than the BHM value of partial equity hybrid funds on the whole from 2007 to 2019, while the condition of SHM index was just the opposite. The overall SHM value of equity funds is higher than that of equity funds. The reason for this phenomenon is that equity funds have $60 \%(80 \%$ after the implementation of the new regulations in August 2015) of the lower limit of positions, while partial equity hybrid funds do not. When there is a lower limit on the position of equity funds, fund managers will choose a more conservative strategy when buying stocks, and are often more inclined to imitate the trading strategies of other funds, investing in "star stocks" in the market, and "hold together for warmth" with other funds in order to avoid liquidity risk and difficulties in adjusting positions when stock prices fall. When market risks arise, fund managers of equity funds will be limited by the minimum position limit and cannot sell a large number of their holdings. This leads to certain subjective trade-offs, which can inhibit follow-up selling to a certain extent. For fund managers of partial equity hybrid funds, they have no such concerns. When individual stocks or market risks increase, they can reduce their positions to zero, which to a certain extent encourages them to make more diversified and more aggressive investments as well as explore the all kinds of stocks in the market, but it also makes them to alternate their positions more frequently, thus it is easier to show strong selling trend. 


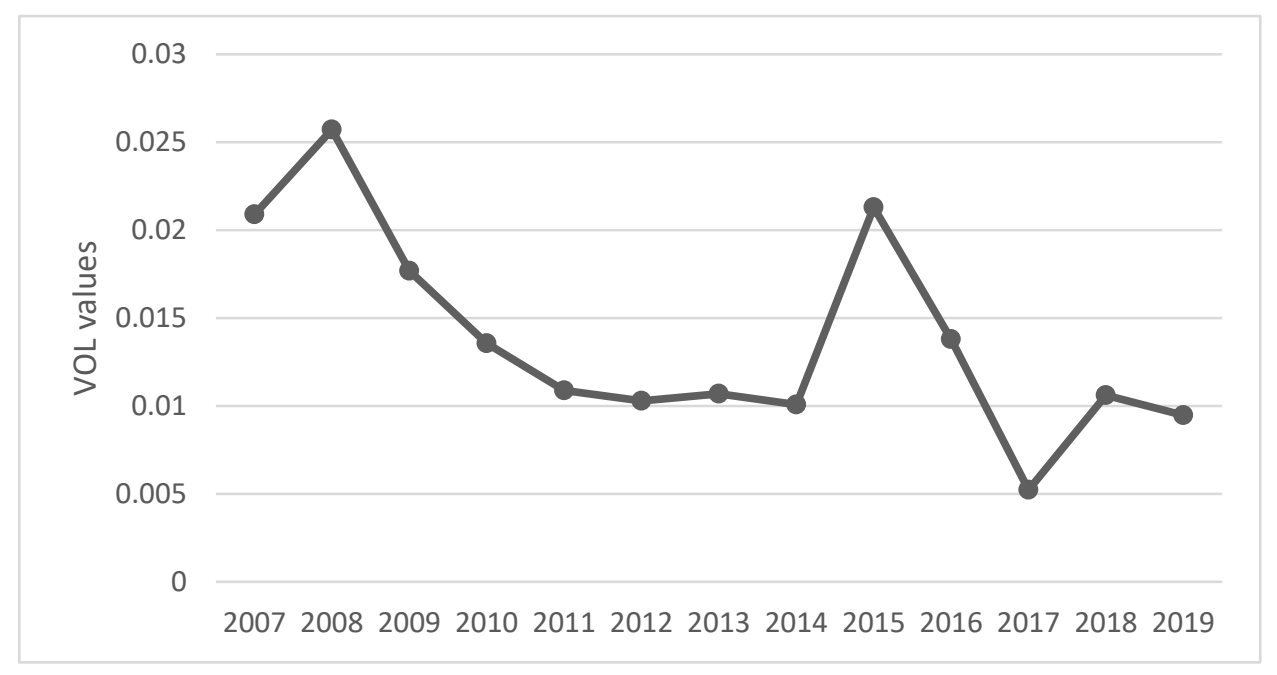

Figure 4. Shanghai Composite Index Volatility Index VOL

Figure 4 shows that VOL had two peaks during the data sample period, which were between 2007 and 2008 and 2015 to 2016, indicating that the volatility of the Shanghai Composite Index was significantly enlarged during these two time periods. In these two time periods, the equity fund's selling herd behavior indicator SHM both rose sharply, while the buying behavior indicator BHM both fell sharply; this phenomenon was also significantly manifested between 2015 and 2016 Of the partial equity hybrid funds. It shows that when the market volatility enlarges, the herd behavior of the two types of funds will increase significantly, and they will urgently sell the stocks in their hands. The decline in the stock price caused by the selling of stocks will intensify the selling herd behavior and form a strong negative feedback process. Conversely, when the market fluctuates violently, the distrust among the funds increases significantly, and the strategy of "hold together for warmth" no longer works, resulting in a significant reduction in the buying effect of the herd. The drastic changes in fund trading strategies will adversely affect the market and increase market volatility.

\section{Conclusions and Policy Recommendations}

The above empirical results show that the equity funds are affected by the minimum position limitation, tending to operate more cautiously. They prefer to follow the trend, and are more likely to exhibit herd behavior in buying behavior than partial equity hybrid funds. While partial equity hybrid funds are the opposite, they have more freedom, tending to change their positions more frequently, which makes it easier to show strong herd behavior in selling. The herd behavior of both funds has an interactive relationship with stock market volatility. Specifically, market volatility exacerbated the selling herd behavior of the two types of funds and inhibited the buying herd behavior. Meanwhile, substantial changes in fund trading strategies will become a booster for market volatility. Based on the above conclusions, this paper gives the following suggestions:

Firstly, for fund companies, the evaluation system should be further improved to avoid excessive focus on short-term performance, so as not to cause fund managers to follow suit in pursuit of short-term performance. Moreover, fund companies should optimize their governance structure, conduct proper supervision of the behavior of fund managers, and avoid excessive concentration of investment.

Secondly, for the regulatory authorities, the regulatory system should be further improved, and an appropriate evaluation system should be established to monitor the overall herd behavior of the market. When the overall herd behavior of the fund is too high, appropriate measures should be taken to restrict the establishment of new funds and instruct funds to diversify their investments, in order to avoid excessive hidden risks and ensure the smooth operation of the financial market.

\section{References}

Abhijit, V. B. (1992). A Simple Model of Herd Behavior. Quarterly Journal of Economics, 107(3), 797-817. https://doi.org/10.2307/2118364

Andrew, K. (2016). Herd Behavior and Mutual Fund Performance. Management Science, 63(11), 3849-3873. https://doi.org/10.1287/mnsc.2016.2543

David, S. S., \& Jeremy, C. S. (1990). Herd Behavior and Investment. American Economic Review, 80(3), 465-479. 
https://www.jstor.org/stable/2006678

Ernst, M., \& Narayan, N. (2011). Herding and Delegated Portfolio Management: The Impact of Relative Performance Evaluation on Asset Allocation. Quarterly Journal of Finance, 1(2), 265-292. https://doi.org/10.1142/S2010139211000092

Lakonishok, J., \& Vishny, R. W. (1992). The impact of institutional trading on stock prices. Journal of Financial Economics, 32(1), 23-43. https://doi.org/10.1016/0304-405X(92)90023-Q

Nerissa, C. B., \& Russ, W. (2014). Analyst Recommendations, Mutual Fund Herding, and Overreaction in Stock Prices. Management Science, 60(1), 1-20. https://doi.org/ 10.1287/mnsc.2013.1751

Nikolaos, P., Fotini, E., \& Alexandros, K. (2013). Herd behavior in REITs: Novel tests and the role of financial crisis. International Review of Financial Analysis, 29, 166-174. https://doi.org/10.1016/j.irfa.2013.01.004

Russ, W. (1999). Mutual Fund Herding and the Impact on Stock Prices. Journal of Finance, 54(2), 581-622. https://doi.org/10.1111/0022-1082.00118

Stelios, B., Mouna, J., Brian, L., \& Gazi, U. (2017). Herd behavior, Market sentiment and Volatility: Will the bubble resume? North American Journal of Economics and Finance, 42, 107-131. https://doi.org/10.1016/j.najef.2017.07.005

Xin, D., \& Zheng, Q. (2018). Mutual Fund Herding and Stock Price Crashes. Journal of Banking and Finance, 94, 166-184. https://doi.org/10.1016/j.jbankfin.2018.07.014

Yilmaz, G., \& Gabriel, K. (2016). Herding in frontier markets: Evidence from African stock exchanges. Journal of International Financial Markets, 47, 152-175. https://doi.org/10.1016/j.intfin.2016.11.001

\section{Copyrights}

Copyright for this article is retained by the author(s), with first publication rights granted to the journal.

This is an open-access article distributed under the terms and conditions of the Creative Commons Attribution license which permits unrestricted use, distribution, and reproduction in any medium, provided the original work is properly cited. 